\title{
VOLUME DE PUBLICAÇÕES CIENTÍFICAS SOBRE EDUCAÇÃO AMBIENTAL NA BASE SCIELO BRASIL: UM ESTUDO DE CIENCIOMETRIA
}

José Nunes da Silva Filho ${ }^{1}$

Resumo: Este estudo teve o objetivo de apresentar o volume da produção científica em Educação Ambiental ao longo dos anos, computados a partir do biblioteca on-line SciELO Brasil. Trata-se de uma pesquisa descritiva com abordagens qualita-quantitativas. $O$ acesso e a busca de dados aconteceram durante a primeira quinzena do mês Abril de 2018, levantando o número total de artigos publicados sobre Educação Ambiental. Foram refinados um volume total de 241 artigos no formato International Organization for Standardization (ISO 690). Conclui-se que especificamente na biblioteca online SciELO, houve ao longo dos últimos anos, um crescimento significativo do número de produção científica acerca do tema Educação Ambiental.

Palavras-chave: Educação; Cienciometria; Produção Científica; Educação Ambiental.

${ }^{1}$ Fundação Gammon de Ensino (FUNGE); Prefeitura Municipal da Estância Turística de Paraguaçu Paulista-SP. E-mail: jose_nunes_99@hotmail.com 


\section{Introdução}

Trata-se de um estudo que se delimitou mostrar através de uma investigação, o número de artigos científicos publicados sobre Educação Ambiental ao longo dos anos na base bibliográfica Scientific Electronic Library Online (SciELO) Brasil. Essa fonte é uma das poucas bases multidisciplinares com elevado grau de representatividade da produção científica realizada nos países em desenvolvimento.

Sabe-se que a Educação Ambiental (EA) vem se tornando uma importante área do conhecimento, que tem por objetivo trazer aos estudantes conhecimentos necessários para que possam exercer a sua plena cidadania, estando cientes de seus direitos e de seu papel fundamental para a sociedade (MELLO; TRAJBER, 2007).

Conceitualmente, a EA é descrita segundo a Lei no 9795/1999, Art.1ํ da Política Nacional de Educação Ambiental, como:

[...] os processos por meio dos quais o indivíduo e a coletividade constroem valores sociais, conhecimentos, habilidades, atitudes e competências voltadas para a conservação do meio ambiente, bem de uso comum do povo, essencial à sadia qualidade de vida e sua sustentabilidade (BRASIL, 1999, p.1).

Nessa perspectiva, acredita-se que devido EA ser um tema de grande relevância para a formação e sustentabilidade da sociedade moderna, é que se justifica a busca por um entendimento melhor sobre o real volume de investigações científicas publicados ao longo dos anos.

Hodiernamente, a ciência e a tecnologia passam por momentos de grandes avanços. Paralelamente, nota-se a presença de diversas técnicas para medir a evolução da ciência e da divulgação do conhecimento científico e de diversas disciplinas do conhecimento (VANTI, 2002).

Entre as técnicas utilizadas atualmente para medição dos avanços da ciência, podemos citar a cienciometria, esta que se define como sendo "[...] a ciência que estuda os aspectos quantitativos de uma determinada área da ciência por meio de indicadores quantitativos que visam medir os incrementos de produção científica de uma área [...] (TAGUE-SUTICKFFE, 1992 apud VANTI, 2002, p.154). Sobre os indicadores quantitativos mais conhecidos nos cenários nacional e internacional, por exemplo, temos o número de trabalhos, que são medidos pela contagem dos trabalhos publicados e, pelo tipo de documento que pode monitorar a dinâmica das pesquisas ao longo dos anos (VANTI, 2002).

O objetivo geral deste trabalho foi apresentar através de um indicador cienciométrico o volume da produção científica de pesquisadores em Educação Ambiental ao longo dos anos, computados a partir da biblioteca on-line SciELO Brasil.

Revbea, São Paulo, V. 14, № 1: 207-221, 2019. 
Esta pesquisa, justifica-se devido ao fato de não ter sido encontrado na literatura, até o presente momento, outro estudo cienciométrico que analisou a mesma temática (volume de publicações sobre Educação Ambiental), bem como a sua relevância em trazer dados que contribuam significativamente para o estado da arte para este campo do conhecimento por situar a produção de um determinado país, instituição, periódicos ou até mesmo de um pesquisador.

\section{Educação Ambiental}

O termo Educação Ambiental (EA), vem sendo frequentemente utilizado entre os mais diferentes meios de comunicação. De acordo com a Organização das Nações Unidas para a Educação, a Ciência e a Cultura (UNESCO, 2005, p. 44), a EA pode ser conceitualmente descrita como "[..] uma disciplina bem estabelecida que enfatiza a relação dos homens com o ambiente natural, as formas de conservá-lo, preservá-lo e de administrar seus recursos adequadamente". Ainda, segundo a Lei 9.795 de 1.999 que dispõe sobre a educação ambiental e institui a Política Nacional de Educação Ambiental e dá outras providências, a EA deve ser entendida como:

Artigo 1을 Entendem-se por educação ambiental os processos por meio dos quais o indivíduo e a coletividade constroem valores sociais, conhecimentos, habilidades, atitudes e competências voltadas para a conservação do meio ambiente, bem de uso comum do povo, essencial à sadia qualidade de vida e sua sustentabilidade.

Além dos entendimentos supracitados, a $A E$, também, pode ser considerada como uma das preocupações sociais de conscientização da utilização adequada dos recursos naturais, seu esgotamento a necessidade de novas ações sociais que sejam voltadas às práticas ambientais apropriadas que levam a sensibilização das pessoas em prol do meio ambiente (CARVALHO, 2017).

Com o passar dos anos, com intuito de melhor utilizá-lo, a sociedade vem causando mudanças significativas no meio ambiente (SANTOS; FARIA, 2004). E, dentre essas mudanças, muitas resultam em danos ambientais catastróficos. Por isso, é que se justifica utilizar da escola - através da educação formal - para estimular os alunos e, por conseguinte a sociedade, a adotarem uma visão mais globalizada e consciente de suas responsabilidades frente ao meio ambiente e a sociedade (LIMA, 2004).

No que tange meio ambiente sustentável, sabe-se que o planeta terra encontra-se em crise e necessitando, urgentemente, de recuperação. Ademais, acredita-se que incluir a EA na educação escolar formal, estabeleceria uma melhor reflexão por parte do indivíduo sobre cidadania, possibilitando assim, uma efetiva participação social, cultural, política e econômica no que se refere 
à preservação do meio ambiente e as condições básicas para a convivência humana futura (MEDEIROS et al., 2011).

Algumas correntes de pensadores acreditam que a EA deva ser tratada na educação formal, através dos temas transversais e de modo interdisciplinar (ZUCCHI, 2002). Subtendendo que questões de tamanha magnitude e importância como no caso do meio ambiente, deva permear por todas as disciplinas e áreas do conhecimento. Em contrapartida, outros autores (CUBA, 2010), acreditam que a EA deveria ser tratada única e exclusivamente como científica, já que, quando trabalhada separadamente - como um tema transversal - acaba ficando esquecida devido ao fato dos conteúdos obrigatórios serem muito extensos ao ponto, muitas vezes, de não ser possível concluí-los até o término do ano letivo. Ainda, segundo o mesmo autor, a EA quando considerada apenas como um tema transversal, acaba não sendo muito levada a sério por parte dos docentes que não se sentem na obrigação de aplicar os tais conteúdos.

Em suma, devido a sua indubitável importância, o que se espera é que tanto como tema transversal, quanto como ciência, que a EA seja trabalhada de maneira efetiva e habitual em todos os níveis de ensino formal já que segundo Libâneo (1998, p.64) "a educação precisa ajudar o aluno a transformar-se em um sujeito pensante, capaz de utilizar seu potencial de pensamento na construção e reconstrução de conceitos, habilidades e valores" e segundo Freitas e Christo (2010, p.04) "Educar é dar condições para que o homem se torne um cidadão justo, solidário e capaz de decidir por si e pela coletividade".

\section{Educação Ambiental no Brasil}

Sobre a EA no Brasil, alguns autores (ZUCCHI, 2002; DE SOUZA; BENEVIDES, 2005) sugerem que o seu início ocorreu a partir da criação dos cursos de Pós-Graduação em Ecologia do Instituto Nacional de Pesquisas da Amazônia (INPA) da Universidade do Amazonas, com início em janeiro de 1.976 (LLERAS, 1981) e o das Universidades de Brasília, Campinas, São Carlos e do Instituto Nacional de Pesquisas Aéreas (INPE) da cidade de São José dos Campos (DE SOUZA; BENEVIDES, 2005).

Por volta de dez anos mais tarde, o Plenário do antigo Conselho Federal de Educação e, atual Conselho Nacional de Educação (CNE), aprovava o Parecer 226 de 1.987, por unanimidade, que considerou imprescindível a inclusão da EA junto aos conteúdos curriculares das escolas de primeiro e segundo graus, sugerindo, ainda, a criação de centros de EA (ZUCCHI, 2002).

A importância da EA aparece indiretamente discutida no Capítulo VI Meio Ambiente - da Constituição Federal de 1.988, bem como em seu Artigo 225: "Todos têm direito ao meio ambiente ecologicamente equilibrado, bem de uso comum do povo e essencial à sadia qualidade de vida, impondo-se ao Poder Público e à coletividade o dever de defendê-lo e preservá-lo para as presentes e futuras gerações", e diretamente no Art. 225, VI - "promover a Revbea, São Paulo, V. 14, № 1: 207-221, 2019. 
educação ambiental em todos os níveis de ensino e a conscientização pública para a preservação do meio ambiente" (BRASIL, 1988).

Passados pouco menos de 10 anos da EA aparecer na Constituição Federal, ela foi contemplada com um capítulo no conjunto de documentos dos Temas Transversais no Parâmetro Curricular Nacional (PCN, 1997). Eleito por envolverem problemáticas de abrangência nacional, o capítulo "Meio Ambiente", contou com a impressão de quase 70 páginas, abordando, primordialmente, a crise ambiental que vive o mundo atual, propondo conteúdos adequados, didáticos e sistematizados para o uso de docentes nas faixas etárias do $1^{\circ}$ e $2^{\circ}$ Ciclos $^{2}$.

Logo em seguida, a ideia da EA ambiental estar presente em todos os níveis e modalidades da educação formal, volta a aparecer com o surgimento da Política Nacional de Educação Ambiental pela Lei 9.795 de 1.999 que "Dispõe sobre a educação ambiental, institui a Política Nacional de Educação Ambiental e dá outras providências", em seu Artigo 10, cita que "[...] $A$ educação ambiental será desenvolvida como uma prática educativa integrada, contínua e permanente em todos os níveis e modalidades do ensino formal" (BRASIL, 1999).

Em seu Artigo 11, a Lei 9.795 de 1.999, assim como o PCN (1997), cita a importância e a necessidade da EA estar presente na formação continuada dos professores em todos os níveis de ensino e em todas as disciplinas curriculares (BRASIL, 1997, p.03):

Art. 11: A dimensão ambiental deve constar dos currículos de formação de professores, em todos os níveis e em todas as disciplinas. Parágrafo único. Os professores em atividade devem receber formação complementar em suas áreas de atuação, dos princípios e objetivos da Política Nacional de Educação Ambiental.

Contudo, torna-se evidente que a Lei 9.765/99, merece ser destacada como sendo um dos principais feitos históricos para a EA no Brasil ao longo dos últimos anos, já que a mesma proporcionou uma concatenação entre diversas áreas profissionais como ambientalistas, docentes e, até mesmo, entre os governos (BRASIL, 1999).

\footnotetext{
2 Segundo a Lei Diretrizes e bases da Educação Nacional, a Educação Básica é composta por: Ciclo I: $1^{\circ}$ ao $5^{\circ}$ ano do Ensino Fundamental; Ciclo II: 6을 ${ }^{\circ}$; e Ciclo III: $1^{\circ}, 2^{\circ}$ e $3^{\circ}$ ano do Ensino Médio (BRASIL, 1.999).
}

revista brasileira educação ambiental 


\section{Scientific Eletronic Library Online}

A Biblioteca Científica Eletrônica On-line (SciELO), cuja a sigla é referente à versão em inglês (Scientific Electronic Library OnLine), é uma "biblioteca eletrônica que abrange uma coleção selecionada de periódicos científicos brasileiros em formato eletrônico" (MENEGHINI, 1998).

Segundo consta no próprio site da SciELO (2018), este projeto foi elaborado através de uma organização da Fundação de Amparo à Pesquisa do Estado de São Paulo (FAPESP) em conjunto com o Centro Latino-Americano e do Caribe de Informações em Ciências da Saúde (BIREME) e vários editores de revistas científicas.

O projeto inicial se propunha a criar mecanismos que catalogasse melhor alguns indicadores como índices de citações e de impacto. E, que paralelamente pudesse melhorar a acessibilidade e a visibilidade da produção científica brasileira por meio eletrônico, gerando maiores e melhores informações sobre a ciência no Brasil, possibilitando assim, novas estratégias e políticas sobre a gestão científica nacional (MENEGHINI, 1998; PACKER, 1998).

Seu início aconteceu com um projeto piloto que envolvia dez periódicos brasileiros de diferentes áreas do conhecimento entre os anos de 1997 e 1998, e que a partir do ano de 2.002, passou a contar com o apoio do Conselho Nacional de Desenvolvimento Científico e Tecnológico (CNPq) e, desde a sua criação, este modelo vem operando regularmente com a inclusão frequente de novos periódicos e sua operação para outros países (SciELO, 2018).

Segundo Parcker (1998), o projeto SciELO além de organizar e publicar textos na integra de revistas Virtuais, produz indicadores do seu uso e impacto, tendo como uma metodologia central, a preparação, armazenando, disseminação e avaliação de publicações científicas em formato eletrônico.

No que se refere ao seu formato e seu conteúdo, à medida em que os resultados do projeto SciELO avançam, sua plataforma passa por atualizações constantemente. Assim, através de sua interface disponível através do link (http://www.scielo.br), é possível um amplo acesso a coleções de periódicos, aos seus fascículos de cada periódico, bem como aos textos completos dos artigos (SciELO, 2018).

$\mathrm{O}$ acesso aos textos na íntegra, pode ser realizado através de índices e formulários de busca. Pois, sua plataforma dispõe de uma interface dinâmica que possibilita a busca de informações científicas de maneira simples e rápida como cita SciELO (2018, p.01):

A interface SciELO proporciona acesso à sua coleção de periódicos através de uma lista alfabética de títulos, ou por meio de uma lista de assuntos, ou ainda através de um módulo de pesquisa de títulos dos periódicos, por assunto, pelos nomes das instituições publicadoras e pelo local de publicação. 
A interface também propicia acesso aos textos completos dos artigos através de um índice de autor e um índice de assuntos, ou por meio de um formulário de pesquisa de artigos, que busca os elementos que o compõem, tais como autor, palavras do título, assunto, palavras do texto e ano de publicação.

Logo, acredita-se que o desenvolvimento da rede SciELO veio para responder às reais necessidades científicas de países em desenvolvimento, como principalmente no caso dos países da América Latina e do Caribe. Esse modelo, proporciona mais visibilidade e acesso universal a literatura científica, visando superar o fenômeno conhecido como "ciência perdida" (SciELO, 2018).

Portanto, fica claro que o desenvolvimento do modelo SciELO foi fundamental para o crescimento e a disseminação de informações científicas geradas pelos periódicos brasileiros, da América Latina e do Caribe.

\section{Cienciometria}

Afim de que novas descobertas científicas possam se transformar em informações acessíveis para a comunidade científica, a publicação dos resultados das pesquisas científicas é considerada, entre os pesquisadores de um modo geral, como um compromisso social "obrigatório". Assim, no que se refere ao desenvolvimento da ciência ao longo dos anos, os indicadores cienciométricos são considerados fundamentais, já que nos últimos anos, esses indicadores puderam contribuir de maneira impar para 0 desenvolvimento e os avanços de novas políticas que se relacionam às práticas científicas, a tecnologia e o progresso econômico e social (MACíASCHAPULA, 2001).

A cienciometria e/ou scientometrics (termo em inglês), resumidamente pode ser definida como "quantificação da ciência" ou "a medição do processo informático", na qual, o termo "informático", significa "a disciplina do conhecimento que estuda a estrutura e as propriedades da informação científica e as leis do processo de comunicação" (MIKHILOV et al. 1969; SPINAK, 1996 apud VANTI, 2002, p.153).

Em outras palavras, a cienciometria se encarrega de avaliar a produtividade, qualidade e a utilização da produção científica através de indicadores numéricos de publicações, patentes, citações, entre outros (SPINAK, 1998).

Quanto a notoriedade do termo cienciometria, sabe-se que o mesmo passou a ter maior visibilidade por volta da década de 1.977, após a publicação da Revista Scientometrics, na Hungria, atual Holanda (TAGUE-SUTCKIFFE, 1992), que originalmente, correspondia a utilização de métodos quantitativos

para estudar a história da ciência e da evolução tecnológica da pesquisa científica (SPINAK, 1998; VANTI, 2002). 
Nas últimas décadas, a cienciometria tornou-se uma das técnicas aplicadas, corriqueiramente, para analisar e conduzir novas informações referentes as publicações nacionais e internacionais da literatura científica. Podendo assim, determinar o quanto que um ou vários países, em um certo período, contribuiu para a literatura científica em determinadas áreas do conhecimento (SCHUBERT; GLANZEL; BRAUN, 1989).

Assim sendo, a cienciometria, pode ser considerada como um mecanismo que produz informações - através de indicadores científicos acerca de situar a produção científica de países, instituições e dos autores. Mecanismo esse, que através de seus indicadores científicos podem realizar análises mais amplas, como por exemplo, a produção científica de um determinado país em um período específico de tempo; bem como análises mais singulares como a produção individual de instituições na produção de artigos em uma área específica do conhecimento (MACIAS-CHAPULA, 1998).

Ademais, a cienciometria desenvolve metodologias próprias para formular indicadores que por meio de técnicas matemáticas, estatísticas, interdisciplinares, econômicas e de administração e documentação podem investigar as principais características das pesquisas científicas (SPINAK, 1998). Segundo o mesmo autor, a cienciometria é mais do que uma simples técnica bibliomética, pois ela consegue examinar 0 desenvolvimento quantitativo de políticas científicas e, assim, estabelecer comparações entre as políticas dos países referentes aos seus aspectos econômicos e sociais.

Não obstante, segundo Sengupta (1992 apud SPINAK,1998, p.143, tradução nossa), a importância das técnicas cienciométricas podem ser notadas ao analisar-se a lista infracitada sobre suas possibilidades de aplicação:

- identificar as tendências e o crescimento do conhecimento nas distintas disciplinas. - estimar a cobertura das revistas secundárias. • identificar os usuários das disciplinas distintas. • identificar autores e tendências em distintas disciplinas. • medir a utilidade dos serviços de disseminação seletiva de informações. • preceder as tendências de publicação. • identificar as revistas do núcleo de cada disciplina. - formular políticas de aquisição ajustadas ao orçamento. • adaptar políticas para descartar publicações. • estudar a dispersão e a obsolescência da literatura científica. • desenhar normas para a padronização. - desenhar processos de indexação, classificação, confecção e resumos automáticos. - prever a produtividade de editores, autores individuais, organizações, países etc.

Portanto, a cienciometria atualmente pode ser considerada uma valiosa ferramenta para as ciências físicas, naturais, sociais e para a ciência da informação. Pois, além de contribuir para o desenvolvimento geral da ciência, contribui, ainda, mesmo que indiretamente, para o desenvolvimento de políticas públicas relacionadas a pesquisa científica. 


\section{Materiais e Método}

Trata-se de uma pesquisa descritiva com abordagens qualitaquantitativa (MARCONI; LAKATOS, 2010), tendo como coleta de dados um levantamento realizado na base de dados SciELO. O acesso e a busca de dados aconteceram durante a primeira quinzena do mês Abril de 2018, sendo levantado o número total de artigos publicados sobre Educação Ambiental.

Para análise estatística dos resultados, limitaram-se a procedimentos descritivos convencionais de análise das frequências e da elaboração dos gráficos expositivos através do Software Excel 2016 (Microsoft Office Professional Plus 2.016) instalado em um Notebook Sony Vaio® (Fit 15S Core i5 Windows 10 Home).

\section{Coleta de dados}

Através da ferramenta de busca do próprio sistema SciELO, o número de artigos publicados na base foi cuidadosamente identificado e compilado em uma lista para análise posterior.

A compilação dos artigos se deu através de 7 etapas (Quadro 1).

Quadro 1: Etapas de busca do volume de artigos sobre EA publicados na SciELO até a primeira quinzena de abril de 2018:

\begin{tabular}{|c|l|}
\hline ETAPAS & \multicolumn{1}{|c|}{ PROCEDIMENTOS } \\
\hline $1^{\circ}$ etapa & $\begin{array}{l}\text { Acesso a página inicial da biblioteca SciELO através do link } \\
\text { (www.scielo.br). }\end{array}$ \\
\hline $2^{\circ}$ etapa & Clique no hiperlink "índice por assuntos". \\
\hline $3^{\circ}$ etapa & $\begin{array}{l}\text { Digitação do termo "Educação Ambiental" no campo "digite a palavra ou } \\
\text { início da palavra e, posteriormente, clicando em "mostrar índice". }\end{array}$ \\
\hline $4^{\circ}$ etapa & $\begin{array}{l}\text { Selecionando o termo "Educação Ambiental" no campo "Selecione um ou } \\
\text { mais termos da lista abaixo" e, clicando no ícone "pesquisa". }\end{array}$ \\
\hline $5^{\circ}$ etapa & $\begin{array}{l}\text { Levantamento e tabulação cronológica dos 241 artigos encontrados } \\
\text { dispostos em 25 páginas, através do filtro de busca. }\end{array}$ \\
\hline $6^{\circ}$ etapa & Construção da tabela de frequência dos anos e volume de publicação. \\
\hline $7^{0}$ etapa & Construção do gráfico de frequência e volume de publicações. \\
\hline
\end{tabular}

Fonte: $O$ autor (2018).

\section{Análise e discussão dos resultados}

Após a inserção do termo em português (Educação Ambiental) e em inglês (Environmental Education), em todos os índices, foram refinados um volume total de 241 artigos no formato International Organization for Standardization (Organização Internacional de Normalização (ISO 690, tradução nossa), visto na Figura 1. 


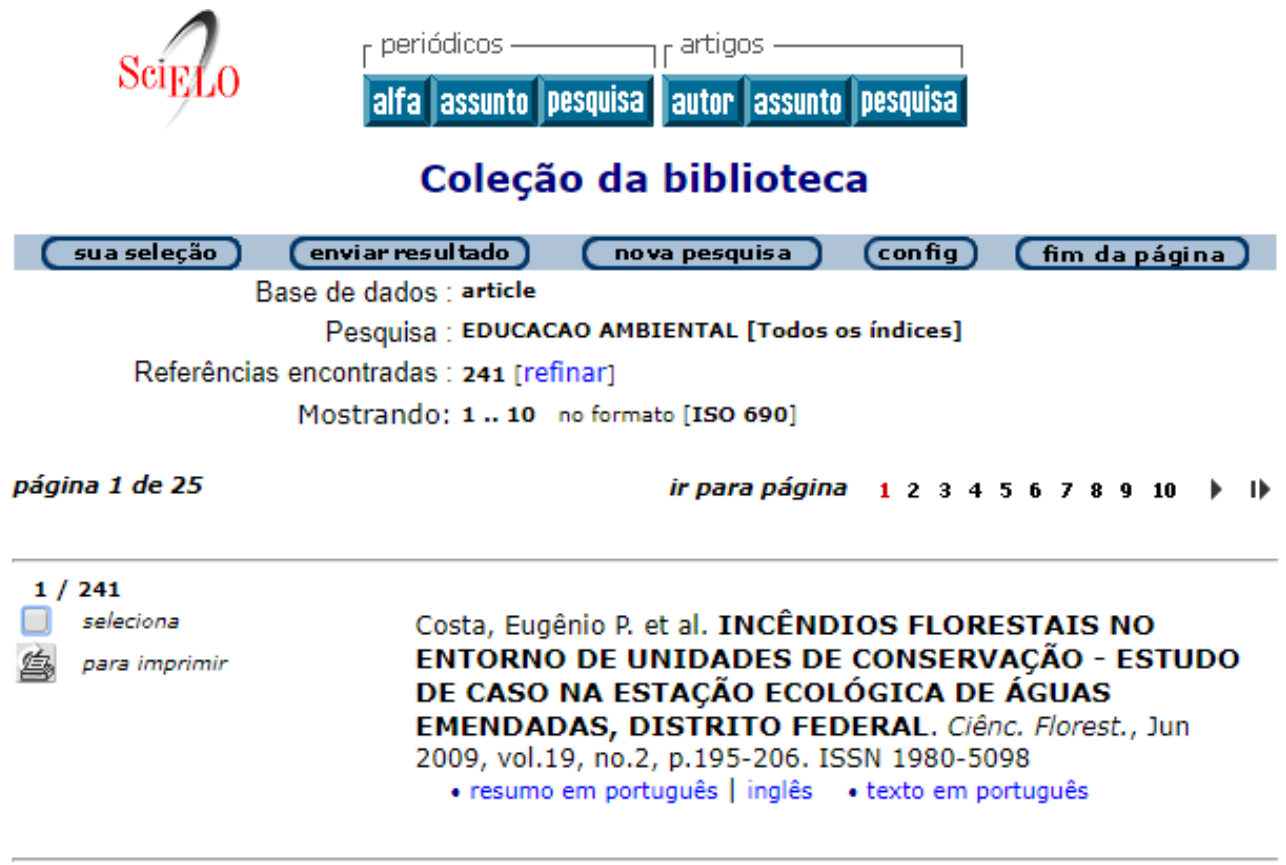

Figura 1: Print da interface SciELO após procedimentos de busca.

Fonte: O autor (2018).

Após separados e catalogados pelo ano de publicação e seus respectivos volumes de artigos, pode-se notar uma frequência crescente de publicações sobre EA ao longo dos últimos anos, bem como o significativo crescimento de publicações nos últimos 10 anos, como visto na Figura 2.

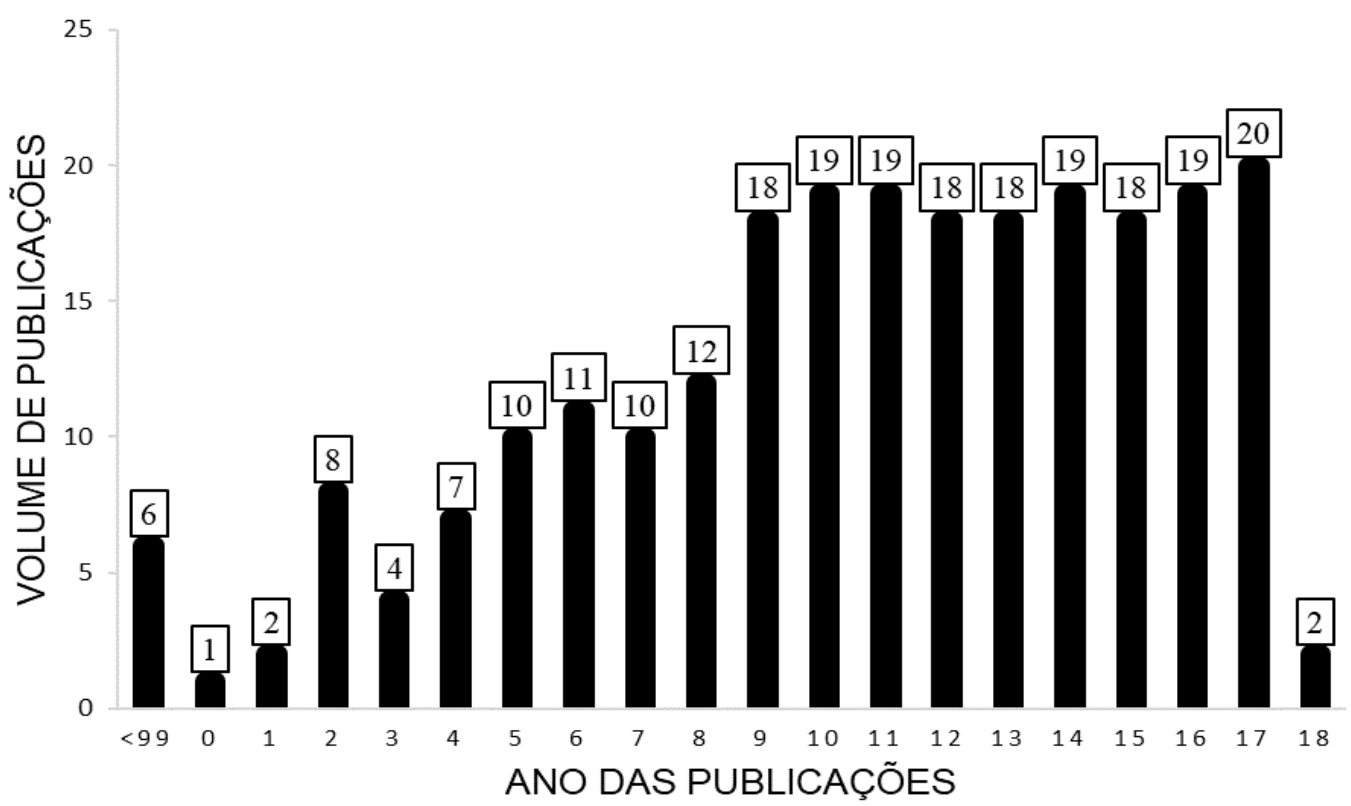

Legenda: <99: artigos publicados antes do ano de 1999; 0 a 18: artigos publicados entre o ano de 2000 ao primeiro trimestre de 2018.

\section{Fonte: $\mathrm{O}$ autor (2018).}


Os dados encontrados no presente estudo, vão de acordo com os achados na literatura (BRAGA, 2002 apud FREITAS; CHRISTO, 2010), que mostram que houve um crescimento considerável - ao longo dos últimos anos em relação às questões ambientais no Brasil e no mundo.

Este crescimento das pesquisas científicas sobre as questões ambientais, vem em conformidade com o crescimento da ciência brasileira ao longo das últimas décadas, descrita pela base do Institute for Scientific Information (ISI). Além disso, pode-se notar que o crescimento nacional quando comparado a outros países da América Latina como Chile, Argentina, Colômbia e México, o brasileiro, foi o mais expressivo (MENEGHINI, 1998).

No entanto, embora visto na presente pesquisa que o Brasil esteja em ascensão no volume de publicações científicas sobre o tema e, esteja entre um dos países que mais se destacou em relação às questões ambientais, em contrapartida, o que se tem feito para amenizar os problemas ambientais referentes aos desastres ecológicos atribuídos as indústrias, ainda, são insuficientes.

Talvez, essa tal insuficiência no combate as catástrofes ambientais no Brasil, se dê devido à falta de uma política de EA. Pois, segundo Zucchi (2002), apesar de a Constituição Federal de 1.998 determinar em um artigo específico sobre a promoção da EA entre todos os níveis de ensino, sabe-se, mesmo assim, que não existe até o presente momento uma política efetivamente implantada na Educação Nacional.

Segundo Carvalho (1992), ao mesmo tempo em que a sociedade exigi a incorporação de uma EA no sistema de ensino, acontece a negativa através das condições objetivas para que isso aconteça. Pois, o estudo realizado por Zucchi (2002, p.15) cita alguns dos diversos fatores que acabam prejudicando e, muitas vezes, impedindo a disseminação de uma EA efetiva e de qualidade:

Carência de recursos, condições precárias de trabalho e insuficiente formação de profissionais do ensino básico são alguns dos problemas mais graves. Pode-se acrescentar, também, a falta de material didático e de apoio de qualidade. Alguns livros sobre Educação Ambiental já foram lançados, mas a maioria possui temática específica ou abrangência nacional. Para incorporar Educação Ambiental a um contexto complexo, como o do ensino básico brasileiro, é preciso articular esforços de vários segmentos da sociedade.

No entanto, além dessa falta de investimento e compreensão da real necessidade de uma EA de qualidade, segundo Silva e Calixto (2013), o que se percebe, atualmente, é que há uma interação conflituosa entre a sociedade e o meio ambiente, uma vez que as questões econômicas alicerçadas em uma visão capitalista extrema, tem estado à frente da qualidade de vida coletiva. 
Assim, torna-se evidente a necessidade de investimentos "reais" e de que novas reflexões sejam incrustradas "efetivamente" no ambiente educacional da sociedade, para que num futuro próximo os problemas ambientais ao longo dos anos, não se tornem uma questão negativa para a sobrevivência da sociedade global.

Para tanto, Carvalho (2008), sugere que tanto os educadores quanto os alunos, possam construir mutuamente esse processo de desenvolvimento de um "sujeito ecológico" 3 . Sujeito esse, que possa analisar, refletir e propor novos mecanismos de interatividade sobre a EA dentro do cotidiano escolar. Em outros termos, o que se espera de uma EA efetiva no âmbito educacional, é que esta possa propiciar às pessoas uma melhor compreensão sobre os recursos naturais existente, criando valores e desenvolvendo atitudes e reflexões conscientes a respeito da conservação e utilização adequada desses recursos, para que assim, haja uma melhor qualidade de vida para a sociedade no mundo todo (MEDINA, 2001).

No que tange ao volume de publicações a respeito da EA, como visto na figura 1, pode-se ver um crescimento considerável a partir dos anos de $2.004 \mathrm{e}$ 2.005 e com maior frequência, ainda, a partir dos anos de 2.009. Estes dados, parecem formar um paralelo ao investimento maciço feito pelo Governo Federal na construção de mais de 100 novos campi da Rede Federal de Educação Superior entre os anos de 2.003 até 2.011 (BRASIL, 2012), gerando um crescimento impar no número de vagas ofertadas nas universidades ferais como comprovado na Figura 3, que mostra um crescimento de aproximadamente $111 \%$ nas Instituições Federais no mesmo período.

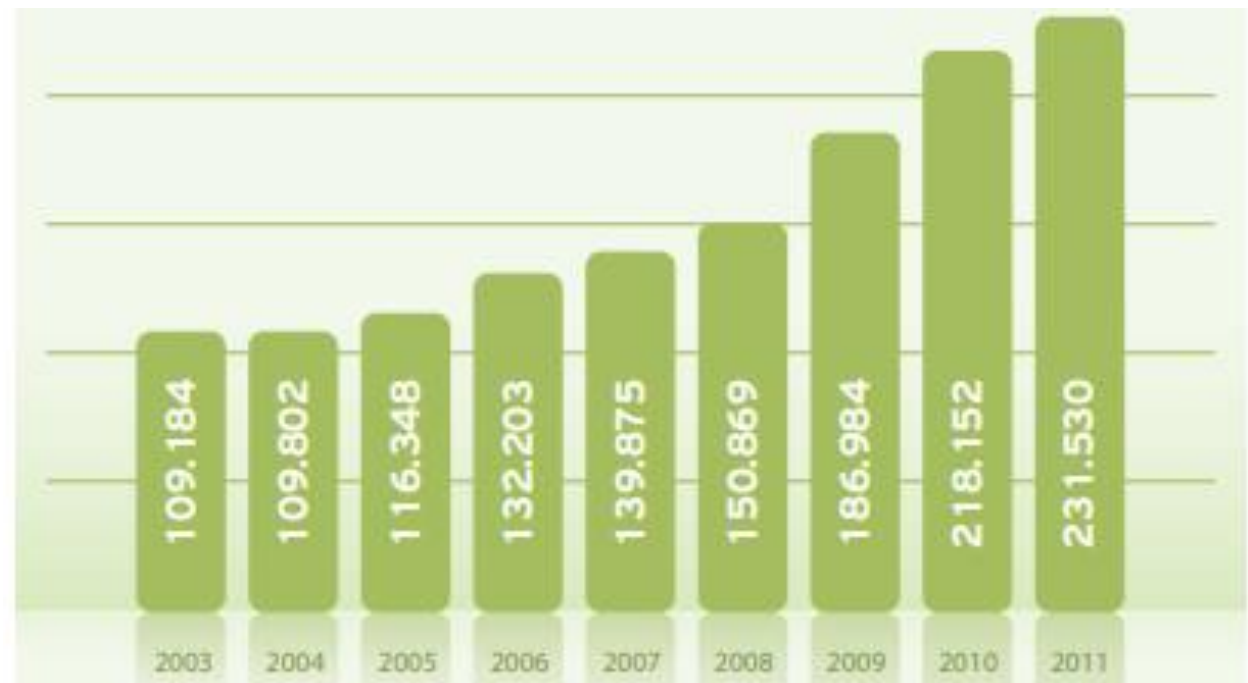

Figura 3: Vagas ofertadas na graduação presencial nas universidades federais.

Fonte: Brasil (2012, p.07)

3 "O sujeito ecológico é aquele com capacidade e sensibilidade para identificar e compreender os problemas ambientais, mobilizando-se e comprometendo-se com as decisões relacionadas ao ambiente equilibrado" (SILVA; CALIXTO, 2013, p.02).

Revbea, São Paulo, V. 14, № 1: 207-221, 2019. 
Por isso, confirma-se o quão é importante para a sociedade oportunizar uma educação gratuita de qualidade, pois sabe-se que:

O acesso adequado e atualizado à informação técnicocientífica é essencial para o desenvolvimento econômico e social, especialmente para apoiar os processos de tomada de decisão na planificação, formulação e aplicação de políticas públicas ou para apoiar o desenvolvimento e a prática profissional (SciELO, 2018, p.01).

Ficou claro que houve um crescimento significativo do volume de publicações sobre a temática abordada nos últimos anos. Crescimento esse, que pode ser explicado por ter havido um volume maior de investimento em educação superior num mesmo período (BRASIL, 2012).

Contudo, sugere-se que novas políticas, investimentos e pesquisa no âmbito da EA seja tema de discussões, afim de se evitar que problemas ambientais comumente observados no estilo de vida da população atual, continue sendo um fator de alarme para a vida coletiva moderna. Já que segundo os dados do Instituto Brasileiro de Geografia e Estatística (IBGE, 2011), os rios localizados nas regiões metropolitanas vêm apresentando cada vez mais, um nível elevado de poluição; na agricultura, observa-se um aumento do uso de agrotóxicos e fertilizantes e na floresta amazônica a progressão dos níveis de desmatamentos. Todos esses fatores supracitados fazem com que a qualidade do ar das grandes cidades gere, num futuro bem próximo, sérios problemas e implicações na saúde dos brasileiros.

\section{Conclusões}

O presente estudo, após analisar o volume da produção científica de pesquisadores em Educação Ambiental ao longo dos anos, computados especificamente a partir da biblioteca on-line SciELO Brasil, conclui que houve ao longo dos últimos anos, um crescimento significativo do número de produção científica acerca do tema Educação Ambiental.

Conclui-se também, a importância de que novos investimentos em políticas públicas relativos ao ensino e a pesquisa em EA aconteçam efetivamente, pois embora o número de investigações científicas sobre o tema esteja em crescimento, este número, ainda, parece tímido frente às reais necessidades brasileiras. 


\section{Referências}

BRASIL. Constituição da República Federativa do Brasil. Brasília, DF: Senado. 1988.

BRASIL. LEI 9.795/1999. Dispõe sobre a Educação Ambiental, institui a Política Nacional de Educação Ambiental e dá outras providências. Brasília, 27 de abril de 1999.

BRASIL. Análise sobre a Expansão das Universidades Federais 2003 a 2012. Relatório da Comissão Constituída pela Portaria no 126/2012. Ministério da Educação/MEC. 2012.

CARVALHO, I.C. Educação, meio ambiente e ação política. In: ASCELARD, H. (Org) Meio Ambiente e Democracia. Rio de Janeiro: IBASE, 1992. p.32-42.

CARVALHO, I.C. Educação Ambiental: a formação do sujeito ecológico. 3.ed. São Paulo: Cortez, 2008. 256p.

CARVALHO, I.C. Educação ambiental: a formação do sujeito ecológico. 6.ed. São Paulo: Cortez, 2017. 256p.

CUBA, M.A. Educação ambiental nas escolas. Educação, Cultura e Comunicação, v. 1, n. 2, p.23-31, 2010.

DE SOUZA, J.N.S; BENEVIDES, R.C.A. Educação Ambiental Para o Desenvolvimento Sustentável e o Comprometimento das Universidades/Faculdades do Município do Rio de Janeiro, RJ. Anais II Simpósio de Excelência em Gestão e Tecnologia, 2005.

FREITAS, S.B; CHRISTO, S.W. Educação Ambiental na Escola. In. O professor PDE e os desafios da escola pública paranaense. V.1, 2010. Disponível em: <http://www.diaadiaeducacao.pr.gov.br/portals/cadernospde/ pdebusca/producoes pde/2010/2010 uepg bio artigo selmara bronoski de f reitas.pdf >. Acessado em: 15.Abr.2018.

IBGE. Atlas de saneamento 2011: Saneamento e meio ambiente. Disponível em: $\quad<$ https://biblioteca.ibge.gov.br/visualizacao/livros/liv53096 cap3.pdf>. Acessado em: 19.Abr.2018.

LIBÃNEO, J.C. Didática. Coleção magistério, Série formação do professor. São Paulo: Cortez, 1994.

LIMA, W. Aprendizagem e classificação social: um desafio aos conceitos. Fórum Crítico da Educação: Revista do ISEP. v. 3, n. 1, 2004.

LLERAS, E. Os Cursos de Pós-graduação do Instituto Nacional de Pesquisas da Amazônia. Acta Amazonica, v. 11, n. 1, p. 117-123, 1981.

MACIAS-CHAPULA, C.A. O papel da informetria e da cienciometria e sua perspectiva nacional e internacional. Ciência da informação, v. 27, n. 2, 1998.

MACÍAS-CHAPULA, C.A. Papel de la informetría y de la cienciometría y su perspectiva nacional e internacional. Acimed, v. 9, p. 35-41, 2001.

MARCONI, M.A.; LAKATOS, E.M. Metodologia da pesquisa cientifica: procedimentos básicos, pesquisa bibliográfica, projeto e relatório, publicações e trabalhos científicos. 7.ed. São Paulo: Atlas, 2010. 244p.

Revbea, São Paulo, V. 14, № 1: 207-221, 2019. 
MEDEIROS, A.B. et al. A Importância da educação ambiental na escola nas séries iniciais. Revista Faculdade Montes Belos, v. 4, n. 1, p.1-17, 2011.

MEDINA, N,M. A formação dos professores em Educação Ambiental. SEF. Panorama da educação ambiental no ensino fundamental. Brasília: MEC/SEF, p. 17-24, 2001.

MELLO, S.S; TRAJBER, R, (coord). Vamos cuidar do Brasil: conceitos e práticas em educação ambiental na escola. Brasília: Ministério da Educação: UNESCO, 2007.

MENEGHINI, R. Avaliação da produção científica e o Projeto SciELO. Ciência da Informação, v. 27, n. 2, p.219-20, 1998.

PACKER, A.L.. SciELO: uma metodologia para publicação eletrônica. Ciência da informação. v. 27, n. 2, p.109-21, 1998.

PARÂMETROS CURRICULARES NACIONAIS - PCN'S. Introdução aos parâmetros curriculares nacionais. Secretaria de Educação Fundamental. Brasília: MEC. 1997. 126p.

SANTOS, E.M; FARIA, L.C.M. O educador e o olhar antropológico. Fórum Crítico da Educaçã. Revista do ISEP. v. 3, n.1, p. 2004.

SILVA, E. L.; CALIXTO, P.M. Educação ambiental na escola: curso de formação para professores. VI Mostra Nacional de Iniciação Científica e Tecnológica Interdisciplinar. Camboriú, 2013. Disponível em:<http://micti2013.ifc.edu.br/anais/resumos/trab00168.pdf>. Acessado em: 15.Abr.2018.

SciELO. Modelo de publicação eletrônica para países em desenvolvimento. Disponível em:< http://www.scielo.org/php/level.php? component $=56$ \&item $=1$ \&lang $=\mathrm{pt}>$. Acessado em 08.Abr.2018.

SCHUBERT, A., GLANZEL, W., BRAUN, T. Scientometric datafiles: a comprehensive set of indicators on 2649 journals and 96 countries in all major science fields and subfields 1981-1985. Scientometrics, n. 16, p. 3-478, 1989.

SPINAK, E. Indicadores cienciométricos. Ciência da informação, v.27, n.2, 1998.

TAGUE-SUTCKIFFE, J. An introduction to informetrics. Information Processing \& Management, v. 28, n. 1, p. 1-3, 1992.

UNESCO. Década da Educação das Nações Unidas para um Desenvolvimento Sustentável, 2005-2014: documento final do esquema internacional de implementação, Brasília, 2005. 120p.

VANTI, N.A.P. Da bibliometria à webometria: uma exploração conceitual dos mecanismos utilizados para medir o registro da informação e a difusão do conhecimento. Ciência da informação, v. 31, n. 2, p. 152-162, 2002.

ZUCCHI, O. J. Educação Ambiental e os Parâmetros Curriculares Nacionais: Um estudo de caso das concepções e práticas dos professores do ensino fundamental e médio em Toledo-Paraná. Florianópolis, 2002. $139 f$. Dissertação (Mestrado em Engenharia de Produção) - Programa de Pósgraduação em Engenharia de Produção, UFSC. 